\title{
Musculoskeletal Disorders: Prevalence and Associated Factors among District Hospital Nurses in Haiphong, Vietnam
}

\author{
Hoang Duc Luan, ${ }^{1,2}$ Nguyen Thanh Hai, ${ }^{2}$ Pham Thu Xanh, ${ }^{3}$ Hoang Thi Giang, \\ Pham Van Thuc, ${ }^{2}$ Nguyen Mai Hong, ${ }^{4}$ and Pham Minh Khue $\mathbb{D}^{2}$ \\ ${ }^{1}$ Phu Tho College of Medicine and Pharmacy, Vietnam \\ ${ }^{2}$ Faculty of Public Health, Haiphong University of Medicine and Pharmacy, Vietnam \\ ${ }^{3}$ Haiphong Department of Health, Haiphong, Vietnam \\ ${ }^{4}$ Rheumatology Department, Bach Mai Hospital, Vietnam
}

Correspondence should be addressed to Pham Minh Khue; pmkhue@hpmu.edu.vn

Received 5 June 2018; Accepted 7 August 2018; Published 26 August 2018

Academic Editor: Bach X. Tran

Copyright (c) 2018 Hoang Duc Luan et al. This is an open access article distributed under the Creative Commons Attribution License, which permits unrestricted use, distribution, and reproduction in any medium, provided the original work is properly cited.

\begin{abstract}
Background. Musculoskeletal disorders (MSDs) are a major occupational health problematic among healthcare workers, and the prevalence is especially high among nurses. In high income countries, the prevention of MSDs is an occupational health priority. But in Vietnam, there is no data available among health professionals. Objectives. To determine the prevalence and associated factors of musculoskeletal disorders among district hospital nurses in Haiphong city. Material and Methods. A cross-sectional study was conducted on 1179 nurses working in 15 district hospitals using the Standardized Nordic Questionnaire. Results. A very high prevalence of MSDs in the past 12 months (74.7\%) and during the last 7 days (41.1\%), with the two most common sites being the low back (44.4\%) and neck (44.1\%), was found; 37.8\% complained that MSDs symptoms limit their work. When analyzing factors related to MSDs, the results showed that women were 2.1 times more likely to develop MSDs than men; people with a previous history of MSDs were more likely to develop MSDs symptoms in the past 12 months than those with no history (OR = 7.1); nurses with symptoms of psychological distress and frequent absenteeism in the workplace had a higher prevalence of MSDs compared to the rest $(p<0.001)$. Conclusions. Due to the high prevalence of MSDs among nurses in district hospitals in Haiphong, preventive actions are needed to improve the working conditions and to raise the awareness of nurses about MSDs prevention.
\end{abstract}

\section{Introduction}

Musculoskeletal disorders (MSDs) are a widespread and increasing occupational health problems in the workplace worldwide. The causes of work-related MSDs are usually multifactorial including physical, ergonomic, and psychosocial factor [1]. MSDs usually occur in workers who have excessive repetition, awkward postures, and heavy lifting [2]. The International Labour Organization (ILO) and the World Health Organization (WHO) regard MSDs as a workrelated disease, which is also referred to as a "new epidemic" that should be researched and solved. MSDs have a huge impact on work-related absence and a high proportion of days lost is due to MSDs [1]. Therefore, it not only affects the health of workers but also creates a burden on the health system, on the businesses economic, and on the social costs to deal with their consequences [1,3]. MSDs prophylaxis is needed in many countries to allow workers to avoid the symptoms of MSDs, improve working productivity, and reduce the burden on medical systems at the same time $[4,5]$. In developed countries, many programs for the prevention of MSDs have been applied on workplace [6].

In the healthcare sector, occupational musculoskeletal disorders are common, with prevalence rates of work-related MSDs reported from $28 \%$ to $96 \%$ over a one-year time period [7], including those among nurses. According to reported data all over the world, nurses have a very high prevalence of MSDs, for example, in Europe, from 10\% to 50\% in France [8], 89\% in Portugal [9], and 85\% in Macedonia [10]; in the Americas, from $35.1 \%$ to $47 \%$ in USA [11] and from $32.8 \%$ to 57.1\% in Brazil [12]; in Africa, $80.8 \%$ in Uganda [13]; and in 
our Asia, 78.6\% in China [14], 85\% in Saudi Arabia [15], and $88 \%$ in Iran [16].

In Vietnam, although the occupational health sector is still underdeveloped, occupational diseases and their prevention are increasingly concerned. Currently, the list of occupational diseases covered by insurance has expanded to 34 [17]. However, MSDs are not included in this list. Many occupational disease prevention programs have been implemented in different work environments, including the medical milieu. Contrariwise, there was only one recent and unique study ever about MSDs among workers in the health sector in Vietnam in 2015 that showed a prevalence of MSDs over the past twelve months among nurses at Viettiep hospital, the largest provincial hospital in Haiphong in the northern coastal region of Vietnam, which was very high (81\%) [18], and many related factors may have affected these disorders [19]. This suggests that the problem of MSDs among nurses in Vietnam can be very large. However, in order to have a comprehensive picture of MSDs among nurses, this study is to assess the current status and risk factors affecting MSDs among nurses at the district hospitals of Haiphong.

\section{Materials and Methods}

2.1. Study Design. A cross-sectional study was designed to determine the prevalence of musculoskeletal disorders (MSDs) and their related factors among nurses working in district hospitals of Haiphong, Vietnam, from January to June 2017.

2.2. Sample Size and Recruitment of Study Subjects. Study subjects included all of nurses working in all of 15 hospitals in districts of Haiphong city, with the following requirements: nursing degree, working time of 12 months or more (this period to ensure an adaptation to the working environment), and agree to participate in this study. Exclusion criteria were as follows: refusal of participation in this study, absence at work at the interview time, or a seniority of less than 12 months. A total of $1179 / 1279$ (participation rate was $92.2 \%$ ) nurses were surveyed.

2.3. Research Instrument and Data Collection. Data were collected through four questionnaires.

(1) A sociodemographic questionnaire was used to collect some general information of participants such as age, gender, height, weight, marital status, average income, and history of musculoskeletal diseases. We also collected information on their working characteristics: working location, department, seniority, working intensity, duration of shift work, and so forth.

(2) Standardized Nordic Questionnaire was developed by Kuorinka et al. in 1987 and was divided into two main parts. The first part evaluates general health problems of musculoskeletal system at different positions on the body during the last 12 months and within the last 7 days. The second part assesses the specific problem of MSDs in each position as well as the consequences it brings to work and the life of the respondent [20]. This questionnaire has been used extensively in many countries around the world for the MSDs study in various groups of subjects and among nursing in special [21].

(3) Psychological distress of Kessler questionnaire (K6) was used to evaluate psychological factors influencing the occurrence of MSDs. This questionnaire has been translated and validated into Vietnamese by Nguyen Thanh Hai et al. in 2013 [22]. The short questionnaire included six questions about a person's emotional state, proven to be able to categorize distress levels for respondents and recommended for use by WHO [23].

(4) The questionnaire evaluating absenteeism at work was developed by the French National Agency for the Improvement of Working Conditions [24], which was used to assess the absence in the past 12 months and allows evaluation of the impact of MSDs on the nurse's work. This survey form consists of 5 questions informing on the number of days off, total number of days off, reasons of absenteeism, and desire to change career or job placement. The Vietnamese version of this questionnaire has been used in several studies in Vietnam [25].

These questionnaires were used by our researcher for direct interviews with the nurses participating in the study. Each interview ranged from 30 to 45 minutes.

2.4. Statistical Analysis. The data was imported and analyzed using SPSS 19.0 version software. We used algorithms for descriptive statistics (percentage, mean, median, standard deviation, and so forth) to describe the sociological characteristics of the participants. The prevalence of MSDs was calculated as the percentage of nurses who developed symptoms of MSDs in at least one of the nine positions on the body (showed in the Nordic Questionnaire). We used chi-squared test when comparing two percentages and $t$-test when comparing two means. Multiple logistic regressions were used to analyze and identify factors associated with MSDs. The models were checked for fitness using HosmerLemeshow's goodness-of-fit test. All analyses were carried out in the Faculty of Public Health, Haiphong University of Medicine and Pharmacy. The level of significance was set at a p-value of less than 0.05 .

2.5. Ethics. The study was approved by the Hai Phong University of Medicine and Pharmacy Institutional Review Board and authorized by the Hai Phong Department of Health to implement at its district hospitals. All nurses participated in the survey were informed and signed the consent of participating in the survey.

\section{Results}

The study involved a total of 1179 nurses working in 15 district hospitals in Hai Phong city, with a participation rate of $92.2 \%$. The number of participants in Thuy Nguyen hospital is highest with 230 nurses, while this number in Cat Hai general district hospital is lowest (16 nurses). The average age of nurses was 32.6 years (in ranging from 19 to 60 , SD \pm 7.7 years). More than $4 / 5$ of the nurses were female (958 
TABle 1: Sociodemographic characteristics of the study group, Haiphong, 2017.

\begin{tabular}{|c|c|c|c|c|c|c|}
\hline Variables & $\mathrm{N}=1179$ & $\mathrm{n}(\%)$ & Mean & Median & Min-max & $\overline{S D}$ \\
\hline \multirow{2}{*}{ Age (years) } & $<45$ & $1087(92.2)$ & \multirow{2}{*}{32.6} & \multirow{2}{*}{31.0} & \multirow{2}{*}{$19-60$} & \multirow{2}{*}{7.7} \\
\hline & $\geq 45$ & $92(7.8)$ & & & & \\
\hline \multirow{2}{*}{ Gender } & male & $221(18.7)$ & & & & \\
\hline & female & $958(81.3)$ & & & & \\
\hline \multirow{4}{*}{ BMI } & $<18.5$ underweight & $134(11.4)$ & & & & \\
\hline & $18.5-22.9$ normal & $842(71.4)$ & & & & \\
\hline & $23-24.9$ overweight & $142(12.0)$ & & & & \\
\hline & $\geq 25$ obesity & $61(5.2)$ & & & & \\
\hline \multirow{5}{*}{ Average income } & $<3$ million VND & $281(23.8)$ & & & & \\
\hline & $3-5$ million VND & $679(57.6)$ & & & & \\
\hline & $5-7$ million VND & $180(15.3)$ & & & & \\
\hline & 7 - 10 million VND & $37(3.1)$ & & & & \\
\hline & $\geq 10$ million $\mathrm{VND}$ & $2(0.2)$ & & & & \\
\hline \multirow{5}{*}{ Marital status } & single & $192(16.3)$ & & & & \\
\hline & married & $972(82.4)$ & & & & \\
\hline & divorced & $8(0.7)$ & & & & \\
\hline & separated & $2(0.2)$ & & & & \\
\hline & widowed & $5(0.4)$ & & & & \\
\hline \multirow{2}{*}{ Has children } & yes & $932(79.1)$ & & & & \\
\hline & no & $247(20.9)$ & & & & \\
\hline Family member & & & 4.2 & 4.0 & $1-20$ & 1.3 \\
\hline \multirow{3}{*}{ Handed } & left handed & $72(6.1)$ & & & & \\
\hline & right handed & $1062(90.1)$ & & & & \\
\hline & both hands & $45(3.8)$ & & & & \\
\hline \multirow{2}{*}{ History of MS disease } & yes & $132(11.2)$ & & & & \\
\hline & no & $1047(88.8)$ & & & & \\
\hline
\end{tabular}

VND: Vietnam dong; MS: musculoskeletal.

females versus 221 males). Most of them have BMI in normal range $(71.4 \%)$, underweight and overweight were $11.4 \%$ and $12.0 \%$, respectively, and the rest was obesity (5.2\%). More than half of them had a monthly income from 3 million to 5 million Vietnam dongs. A significant number of nurses were married $(82.4 \%)$, and the percentage of participants had at least one child was exactly $79.1 \%$. The average of members in a family was 4.2 persons. A large number of them $(90,1 \%)$ were right-handed people. Furthermore, the people who have experienced musculoskeletal diseases were $11.2 \%$ (Table 1).

In terms of working position, nurses were divided into two types of jobs: administrative (9.4\%) and clinical (90.6\%). Nurses who frequently work at least 10 hours each day was $37.2 \%$. The number of nurses who have been taking responsibilities on their duty was $68.3 \%$ with the distance between two duties being 5.2 days ( $\mathrm{SD} \pm 1.5$ days). The average time spent on the work per week was around 49.5 hours (SD \pm 11.3 hours). The average of anxiety score was 4.5 (SD \pm 3.7 ) (Table 2).

Table 3 shows the data about the percentage nurses who were absent in working place during the last 12 months; it was $48.6 \%$. The average of absence day were 24.7 days (SD \pm 52.8 days), while their median was only 5 days. In detail, the reasons for their absence were commonly involved in their own families (family work, maternity leave, and so forth) which accounted for $90.1 \%$ of nurses, followed by short-term illness $(8.6 \%)$. A few of them $(6.5 \%)$ considered that the working conditions were a major reason for their absence and there was only a very little proportion of people who wanted to be sent to another position or change their jobs.

According to the results from Nordic Questionnaire, the study revealed that the percentage of nurses suffered from MSDs during the last 12 months was $74.7 \%$. In addition, the symptoms in the low back and the neck were highest at $44.4 \%$ and $44.1 \%$, respectively. Around $37.8 \%$ of nurses reported that MSDs obstructed their works. $41.1 \%$ of nurses had MSDs symptoms during the last 7 days (Figure 1).

In Figure 2, sorted by hospital, Kien An and Kien Thuy were two hospitals in which nurses had the highest prevalence of MSDs during the last year, 93.5\% and 90.1\%, respectively. Meanwhile, this proportion of nurses working at Thuy Nguyen hospital was the lowest (59.9\%).

In order to find out some related factors of MSDs, multivariate statistics were used (Table 4). The results indicated that age, history of musculoskeletal disease, anxiety, and absenteeism in the workplace were statistically significant factors in MSDs during the last 12 months among nursing. In detail, the odds of MSDs in women are 1.1 times greater than 
TABLE 2: Work characteristics and psychological distress level among nurses in Haiphong, 2017.

\begin{tabular}{|c|c|c|c|c|c|c|}
\hline Variables & $\mathrm{N}$ & $\%$ & Mean & Median & $\mathrm{SD}$ & Min-max \\
\hline \multicolumn{7}{|l|}{ Department } \\
\hline Medicine & 183 & 15.5 & & & & \\
\hline Surgery & 105 & 8.9 & & & & \\
\hline Obstetrics \& Gynaecology & 91 & 7.7 & & & & \\
\hline Pediatric & 53 & 4.5 & & & & \\
\hline Others & 747 & 63.4 & & & & \\
\hline \multicolumn{7}{|l|}{ Working position } \\
\hline Administrative & 111 & 9.4 & & & & \\
\hline Clinical & 1068 & 90.6 & & & & \\
\hline Regularly work $>10$ hours / day & 438 & 37.2 & & & & \\
\hline Working day / week & 1179 & & 5.3 & 5.0 & 0.5 & $5-7$ \\
\hline Distance of duty (day) & 805 & 68.3 & 5.2 & 5.0 & 1.5 & $1-8$ \\
\hline Working hours / week & 1179 & & 49.5 & 48.0 & 11.3 & $20-99$ \\
\hline Score on anxiety level & 1179 & & 4.5 & 4.0 & 3.7 & $0-19$ \\
\hline
\end{tabular}

TABLE 3: Absenteeism pattern during the last 12 months among nurses in Haiphong, 2017.

\begin{tabular}{|c|c|c|c|c|c|c|}
\hline & $\mathrm{N}=1179$ & $\mathrm{n}(\%)$ & Mean & Median & Min-max & SD \\
\hline Absenteeism & & $573(48.6)$ & & & & \\
\hline Number of absence & & & 3.1 & 2 & $0-30$ & 3.7 \\
\hline Total of absence (day) & & & 24.7 & 5 & $1-210$ & 52.8 \\
\hline \multirow{6}{*}{ Cause of absence } & long-term illness (over 2 weeks) & $5(0.9)$ & & & & \\
\hline & short-term illness (less than 2 weeks) & $49(8.6)$ & & & & \\
\hline & occupational disease & $3(0.5)$ & & & & \\
\hline & occupational accident & $0(0)$ & & & & \\
\hline & traffic accident & $11(1.9)$ & & & & \\
\hline & others (maternity leave, house work...) & $516(90.1)$ & & & & \\
\hline $\begin{array}{l}\text { Working conditions lead } \\
\text { to absent }\end{array}$ & & $37(6.5)$ & & & & \\
\hline \multirow{5}{*}{$\begin{array}{l}\text { Desire to change } \\
\text { positions or change jobs }\end{array}$} & never & $884(75)$ & & & & \\
\hline & rarely & $114(9.7)$ & & & & \\
\hline & sometimes & $165(14)$ & & & & \\
\hline & regularly & $10(0.9)$ & & & & \\
\hline & always & $6(0.5)$ & & & & \\
\hline
\end{tabular}

in men $(p<0.001)$; participants who had a medical history related to musculoskeletal disease previously were easier to develop MSDs than those who did not $(\mathrm{OR}=7.1 ; p<0.001)$; the nurses with anxiety in their lives and who have been absent at work will have higher prevalence of MSDs than those who did not have these elements (all of $p$-value were less than 0.001 ).

\section{Discussion}

Our study included a total of 1179 nurses currently working in 15 district hospitals in Hai Phong City, Vietnam. Workrelated MSDs on the past 12 months were observed in 881 nurses $(74.7 \%)$ and during the last 7 days were $41.1 \%$ and these disorders obstruct the work of $37.8 \%$ of nurses. The most common site affected was the lower back in $44.4 \%$ and the neck in $44.1 \%$, followed by the upper back (32.7\%) and the shoulder (29.7\%). The significant related factors were sex (female), having a history of musculoskeletal disease, anxiety, and absenteeism.

Numerous previously studies throughout the world have shown the very different prevalence of MSDs on nurses over a 12-month period. This result was relatively similar to the other studies on nursing such as $79.5 \%$ in Turkey [26], 76\% in India [27], $76.2 \%$ in long-term study from 2004 to 2010 in 3915 nurses in Taiwan [28], 70\% in Poland [29], 78\% in Nigeria [30], and 79.5\% in China [14]. However, this result was lower than those observed in Uganda in 2013 among 755 nurses (80,8\%) [13], in Estonia (84\%) [31], 89\% in Portugal [9], in Macedonia (85\%) [10], and $80.8 \%$ in Uganda [13] and, in our Asia, there were Saudi Arabia (85\%) [15], Iran (88\%) [16], and Japan (85.5\%) [32]. On the contrary, this prevalence was higher than that in France (from 10\% to 50\%) [8], in 


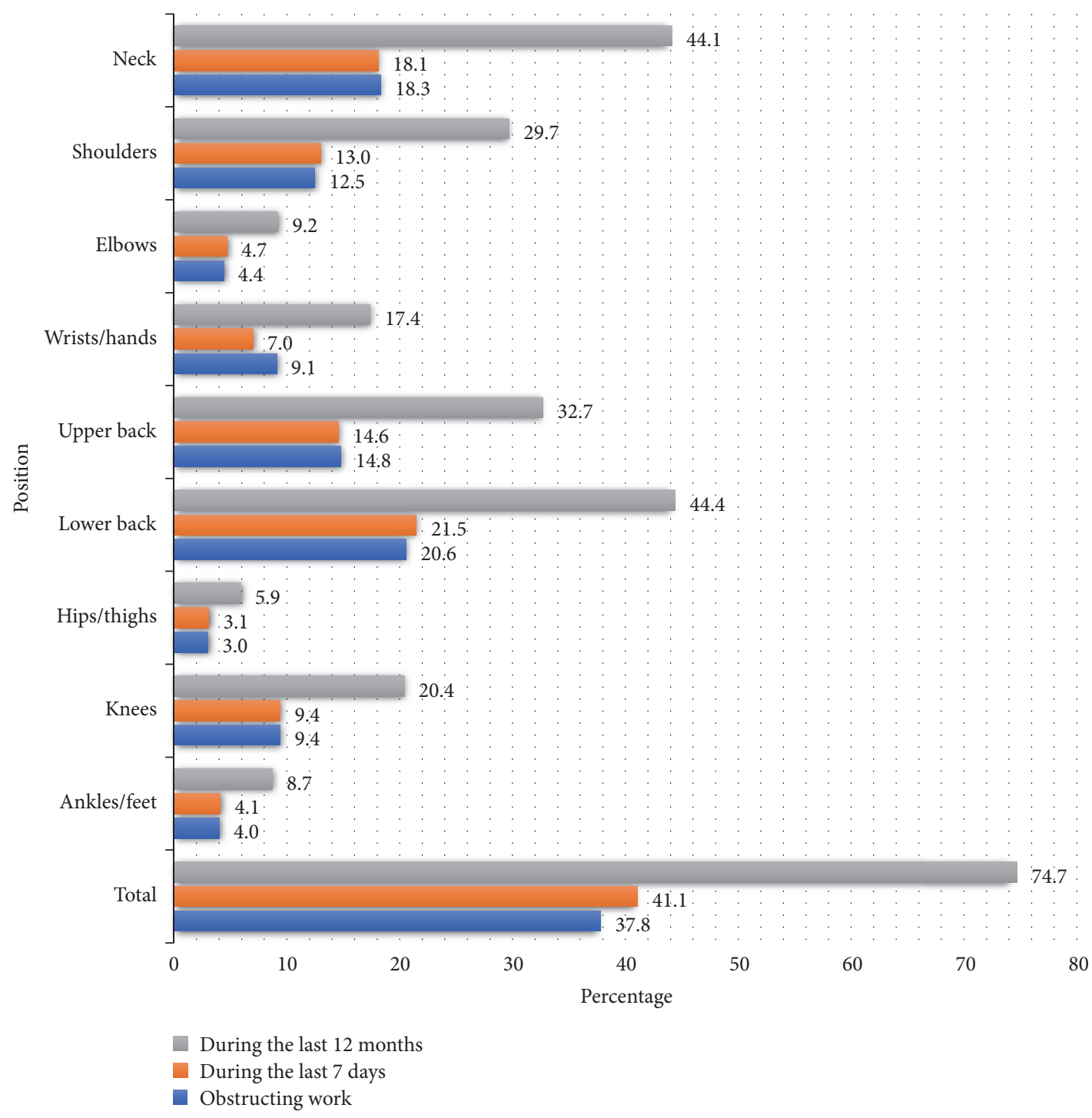

FIGURE 1: Types of musculoskeletal disorders among nurses in Haiphong, 2017.

USA (from $35.1 \%$ to $47 \%$ ) [11], and (from $32.8 \%$ to $57.1 \%$ ) in Brazil [12]; in Pakistan (31.6\%) [33], in Thailand (47.8\%) [34], and in Malaysia (from $35.3 \%$ to $48.9 \%$ ) [35]. There were possibly two reasons for these differences: firstly, it depends on the nursing work condition and characteristics of each continent, each country, and each region; secondary, a higher frequency is contributed by the number of symptoms of MSDs which appears in the assessment questionnaire. In this study, we used the Standardized Nordic Questionnaire with 3 references symptoms: ache, pain, and discomfort, while others symptoms may be included: numbness, stiffness, and so forth.

The most common site affected in this study was the lower back (44.4\%) and the neck (44.1\%). The results of some studies in Asia are comparable to this result; for example, in Pakistan in 2015, it was illustrated that around $49.7 \%$ of nurses faced MSDs in their lumbar, and 35.4\% of them complained about MSDs in their shoulders [36]; another study in Iran and in Hong Kong saw the same picture with $40 \%$ and $42 \%$, respectively, of nurses reporting MSDs in their lumbar $[37,38]$; and one study in Nigeria (in Africa) showed that the rate of MSDs in lower back was 44.1\% [30]. Although most studies have shown that lower back was the most common site, this prevalence was still modest when compared to that from other studies in Asia: in Japan (lower back 71.3\%) [32], in Iran $(73.2 \%$ in 2010 and $65.3 \%$ in 2014) $[16,39]$, in China (64.83\%) [14], and in Saudi Arabia (65.7\%) [15]; and this was similar to other studies in Europe: in Portugal (60.9\% in 2015 and $63.1 \%$ in 2017) $[9,40]$ and in Slovenia (85.9\%) [41]. Neck was also one of the most common sites of MSDs. Results in this study are similar to those of some other studies such as $46.3 \%$ in Iran [39], $42.8 \%$ in China [42], and $48.94 \%$ in Malaysia [35].

When studying the factors associated with MSDs among nurses, the results indicated several related factors that were statistically significant. Regarding gender, the odds of 


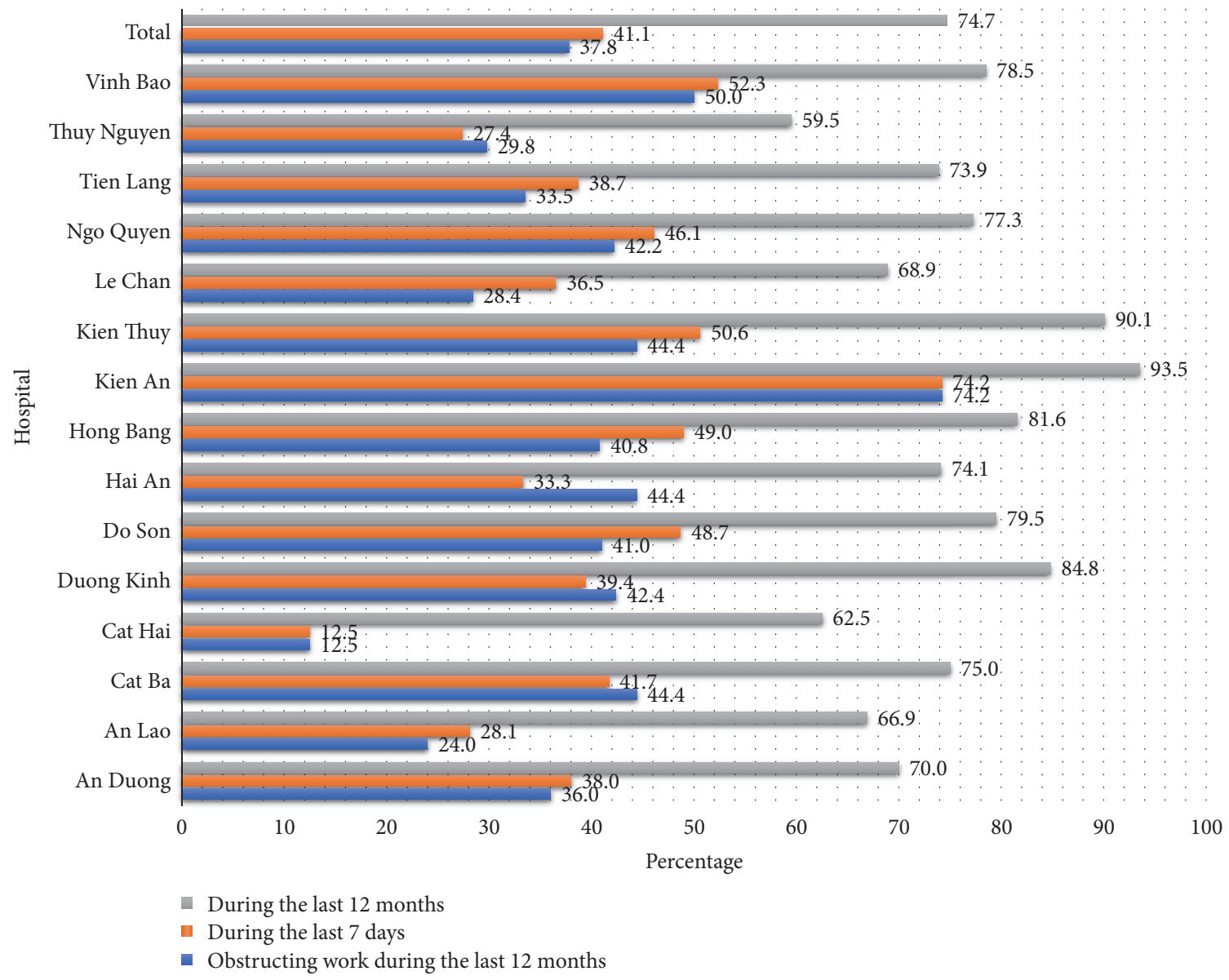

Figure 2: Musculoskeletal disorders characteristics among nurses by hospitals, Haiphong, 2017.

disorder in female are 1.1 times greater than male. This can be understood as women have lower adaptive status than men in patient-related activities, such as patient transport and infusion. History of musculoskeletal diseases in the past has been a factor in the development of MSDs. When an individual suffers from previous musculoskeletal diseases, the adaptive capacity of the musculoskeletal system to activity will be reduced; combined with inappropriate manipulations and postures in working, these conditions will motivate and generate the manifestations of MSDs. The absence at the workplaces was also a related factor to MSDs. Our results shown that this absence was one of potential risks for occupational MSDs. But within the scope of this article, it was also a limitation of this study that we have not considered the opposite, meaning the impact of MSDs on workplace absences and other consequences. In the literature, European Agency for Safety and Health at Work has demonstrated in their report in 2010 that "a high proportion of days lost in the Member States of the European Union is due to MSDs and absences are often long" [1]. In order to establish this conclusion, we need to conduct further study in the future. The last related factor that we have identified in the analytical model was anxiety. It was evident that the level of anxiety in daily life was one of the risk factors of MSDs. When a nurse has anxiety issues in common life, for example, about her/his family and her/his difficulties in work as well as in life, these will follow them to the work environment and affect the ability and concentration in work and the operation will no longer accurate because they lose their attention and cannot focus on their work. It can be a potential reason for MSDs. Anxiety was known to be associated with musculoskeletal disorders among healthcare workers including nurses [34, $43,44]$. From a psychological perspective, looking after patients with chronic diseases is associated with anxiety [45]. Biologically, anxiety is associated with inflammation [46, 47]. Nevertheless, majority of people suffering from anxiety fail to acknowledge the underlying psychiatric conditions and result in delayed treatment. It is important to offer early intervention to treat anxiety among nurses to prevent musculoskeletal disorders. Numerous studies have identified relevant factors similar to the results of our study: female gender [41, 48], absenteeism [9], and psychosocial factors $[8,12,16,31,32,34,35,39,42,48-51]$. In Vietnam, a previous study in Haiphong in Vietiep hospital (which have the largest number of nurses) also illustrated some factors as the gender, stress, and high age associated with MSDs [19], which was similar to our study outcomes.

This study has several limitations. Similar to many other studies using the Nordic Questionnaire, the process of data collection through interviews of events in the past 12 
TABLE 4: Factors associated with musculoskeletal disorders among nurses of district hospitals in Haiphong, 2017.

\begin{tabular}{|c|c|c|c|c|c|}
\hline \multirow{2}{*}{ Independent variables } & & MSDs & Crude $\mathrm{OR}^{\mathrm{a}}$ & Adjusted $\mathrm{OR}^{\mathrm{b}}$ & \multirow{2}{*}{$p$-value ${ }^{c}$} \\
\hline & & n (\%) & OR [IC 95\%] & OR [IC 95\%]* & \\
\hline \multirow{2}{*}{ Age } & $<45$ & $809(74.4)$ & ref & & \multirow{2}{*}{0.425} \\
\hline & $\geq 45$ & $72(78.3)$ & $1.2[0.7-2.1]$ & $1.3[0.7-2.2]$ & \\
\hline \multirow{2}{*}{ Gender } & male & $136(61.5)$ & ref & ref & \multirow{2}{*}{$<0.001$} \\
\hline & female & $745(77.8)$ & $2.2[1.6-3.0]$ & $2.1[1.5-2.9]$ & \\
\hline \multirow{2}{*}{ Overweight } & no & $736(75.4)$ & ref & ref & \multirow{2}{*}{0.734} \\
\hline & yes & $145(71.4)$ & $0.8[0.6-1.1]$ & $0.9[0.7-1.4]$ & \\
\hline \multirow{2}{*}{ Working hours/week } & $<40$ hours & $6(60)$ & ref & ref & \multirow{2}{*}{0.417} \\
\hline & $\geq 40$ hours & $875(74.9)$ & $2.0[0.6-7.1]$ & $1.7[0.5-6.5]$ & \\
\hline \multirow{2}{*}{$\begin{array}{l}\text { History of musculoskeletal } \\
\text { disease }\end{array}$} & no & $756(72.2)$ & ref & ref & \multirow{2}{*}{$<0.001$} \\
\hline & yes & $125(94.7)$ & $6.9[3.2-14.9]$ & $7.1[3.2-15.5]$ & \\
\hline \multirow{2}{*}{ Work position } & administrative & $85(76.6)$ & ref & ref & \multirow{2}{*}{0.669} \\
\hline & clinical & $796(74.5)$ & $0.9[0.6-1.4]$ & $1.1[0.7-1.9]$ & \\
\hline \multirow{2}{*}{ Working $>10$ hours/day } & no regularly & $548(74)$ & ref & ref & \multirow{2}{*}{0.168} \\
\hline & regularly & $333(76)$ & $1.1[0.8-1.5]$ & $1.2[0.9-1.7]$ & \\
\hline \multirow{2}{*}{ Working day/week } & $\leq 5$ days & $664(74.9)$ & ref & ref & \multirow{2}{*}{0.691} \\
\hline & $>5$ days & $217(74.1)$ & $0.96[0.7-1.3]$ & $0.9[0.7-1.3]$ & \\
\hline \multirow{2}{*}{ On duty } & no & $292(78.1)$ & ref & ref & \multirow{2}{*}{0.093} \\
\hline & yes & $589(73.2)$ & $0.8[0.6-1.02]$ & $0.7[0.5-1.1]$ & \\
\hline \multirow{2}{*}{ Anxiety } & no & $538(71)$ & ref & ref & \multirow{2}{*}{$<0.001$} \\
\hline & yes & $343(81.5)$ & $1.8[1.3-2.4]$ & $1.8[1.3-2.4]$ & \\
\hline \multirow{2}{*}{ Absenteeism } & no & $420(69.3)$ & ref & ref & \multirow{2}{*}{$<0.001$} \\
\hline & yes & $461(80.5)$ & $1.8[1.4-2.4]$ & $1.7[1.3-2.3]$ & \\
\hline
\end{tabular}

${ }^{\mathrm{a}}$ Univariate analysis; ${ }^{\mathrm{b}}$ multiple logistic regression; ${ }^{\mathrm{c}}$ likelihood-ratio test. MSDs: musculoskeletal disorders; OR: odds ratio; CI: confidence interval. $\alpha<0.05$.

months may cause recall bias when answering the question, especially the recall of MSDs symptoms. Nevertheless, the investigators have been well trained and have tried to exploit these events carefully to limit this bias. In Vietnam, nursing work characteristics are divided into two major categories: clinical nursing, direct contact with the patient and related operations involving infusion or transport of patients; administrative nursing, nurses who do not contact patients and their work being only related to administrative procedures and patient records management. Our study was conducted on both types of nurses mentioned above with different work characteristics, so the prevalence of MSDs gained has not reflected all the characteristics of these different work types. However, research has still achieved this priority goal, which is to indicate the common prevalence of MSDs. In the exclusion criteria, our study was able to exclude other persistent musculoskeletal diseases from the beginning of the survey, this allowed us to assess current symptoms of MSDs without taking into account preexistent pathologies such as congenital spine disorders, trauma, and pain due to surgery or other diseases. Regarding logistic regression analysis, we were unable to cover all factors in the literature that could affect the MSDs such as working seniority, break time during working, division by particularly for each department, especially those with high working intensity, and unsuitable working positions (surgery, anesthesia, obstetric, and emergency). Nevertheless, the factors that we have exploited had been considering of their suitability in the context of our country and we hope to delve some wider range of factors in future studies.

The strong point of this study is that it is one of the first studies in Vietnam on work-related MSDs generally and on work-related MSDs among nurses specially. The scale of this study is quite large with high participation rates. The research population is highly representative for nurses in general, covering almost all nurses currently working in Haiphong city. This allows objective evaluation of the study results and reflects the current situation of MSDs among nurses in Vietnam. From there, it will make the premise and open up the prospects for further studies in Vietnam on professional MSDs specially and on occupational health generally.

\section{Conclusion}

A high prevalence of MSDs (74.7\%) in nurses was found in this study, with the two most common sites being the lower back (44.4\%) and the neck (44.1\%). Some related factors were included: female gender, history of musculoskeletal diseases, 
absenteeism, and anxiety. More research will be needed in the future with more accurate data to provide the basis for future prevention measures to reduce the prevalence, incidence, and consequences of MSDs.

\section{Data Availability}

The EXCEL/SPSS data used to support the findings of this study are available from the corresponding author upon request.

\section{Disclosure}

The funding agencies did not interfere with either the design of the study or the interpretation of the results.

\section{Conflicts of Interest}

The authors have no conflicts of interest to report.

\section{Authors' Contributions}

Hoang Duc Luan and Nguyen Thanh Hai contributed equally to this study.

\section{Acknowledgments}

The authors would thank faculty members and students of the Faculty of Public Health, Haiphong University of Medicine and Pharmacy, for participating in data collection of this study; they would like to dedicate also special thanks to direction boards and human resources officers of 14 district hospitals of Haiphong who have facilitated the access to the hospital human resource data and interviewing nurses. This work was co-supported by the Haiphong University of Medicine and Pharmacy, Haiphong Department of Health, and Phutho College of Pharmacy, Vietnam.

\section{References}

[1] European Agency for Safety and Health at Work, Ed., OSH in figures: work-related musculoskeletal disorders in the EU - Facts and figures, Office for Official Publ. of the Europ. Communities, Luxembourg, 2010.

[2] B. R. Da Costa and E. R. Vieira, "Risk factors for workrelated musculoskeletal disorders: a systematic review of recent longitudinal studies," American Journal of Industrial Medicine, vol. 53, no. 3, pp. 285-323, 2010.

[3] S. Bevan, "Economic impact of musculoskeletal disorders (MSDs) on work in Europe," Best Practice \& Research Clinical Rheumatology, vol. 29, no. 3, pp. 356-373, 2015.

[4] A. Luttmann, M. Jäger, B. Griefahn, G. Caffier, F. Liebers, and U. Steinberg, Preventing musculoskeletal disorders in the workplace, Protecting Workers' Health Series, World Health Organization, Geneva, Switzerland, 5th edition, 2003, Available from: http:// www.who.int/occupational_health/publications/en/oehmsd3 .pdf.

[5] S. Caroly, F. Coutarel, E. Escriva et al., La prévention durable des TMS: Quels freins? Quels leviers d'action? (Rapport de recherche) PACTE; ANACT; LEEST; Equipe d'Ergonomie Bordeaux; 2008.

[6] Z. Podniece and T. N. Taylor, Work-related musculoskeletal disorders: prevention repor, Office for Official Publications of the European Communities, Luxembourg, 2008.

[7] S. P. Anderson and J. Oakman, "Allied Health Professionals and Work-Related Musculoskeletal Disorders: A Systematic Review," Safety and Health at Work, vol. 7, no. 4, pp. 259-267, 2016.

[8] C. Pelissier, L. Fontana, E. Fort et al., "Occupational risk factors for upper-limb and neck musculoskeletal disorder among health-care staff in nursing homes for the elderly in France," Industrial Health, vol. 52, no. 4, pp. 334-346, 2014.

[9] T. Ribeiro, F. Serranheira, and H. Loureiro, "Work related musculoskeletal disorders in primary health care nurses," Applied Nursing Research, vol. 33, pp. 72-77, 2017.

[10] A. Bitsios, A. Gioftsidou, P. Malliou, and A. Beneka, "Musculoskeletal disorders and their burden on nursing staff," Nosileft$i k i$, vol. 53, no. 2, pp. 185-192, 2014.

[11] A. M. Trinkoff, J. A. Lipscomb, J. Geiger-Brown, and B. Brady, "Musculoskeletal problems of the neck, shoulder, and back and functional consequences in nurses," American Journal of Industrial Medicine, vol. 41, no. 3, pp. 170-178, 2002.

[12] N. d. Fonseca and R. d. Fernandes, "Factors Related to Musculoskeletal Disorders in Nursing Workers," Revista LatinoAmericana de Enfermagem, vol. 18, no. 6, pp. 1076-1083, 2010.

[13] I. G. Munabi, W. Buwembo, D. L. Kitara, J. Ochieng, R. C. Nabirye, and E. S. Mwaka, "Musculoskeletal disorders among nursing staff: A comparison of five hospitals in Uganda," Pan African Medical Journal, vol. 17, article no. 81, 2014.

[14] P. Yan, F. Li, L. Zhang et al., "Prevalence of Work-Related Musculoskeletal Disorders in the Nurses Working in Hospitals of Xinjiang Uygur Autonomous Region," Pain Research \& Management, vol. 2017, Article ID 5757108, 7 pages, 2017.

[15] S. M. Attar, "Frequency and risk factors of musculoskeletal pain in nurses at a tertiary centre in Jeddah, Saudi Arabia: a cross sectional study," BMC Research Notes, vol. 7, no. 1, article 61, 2014.

[16] N. Arsalani, M. Fallahi-Khoshknab, M. Josephson, and M. Lagerström, "Musculoskeletal disorders and working conditions among iranian nursing personnel," International Journal of Occupational Safety and Ergonomics, vol. 20, no. 4, pp. 671680, 2014.

[17] Vietnam Ministry of Health, "Circular on regulations on occupational diseases covered by social insurance," 15/2016/TT-BYT, 2016.

[18] N. Q. Kieu, D. L. Hoang, M. K. Pham et al., Organizational characteristics and musculoskeletal disorders among nurses at Viet Tiep hospital in Hai Phong in 2015, XXV (11-171): 107-113, 2015.

[19] N. Q. Kieu, D. L. Hoang, M. K. Pham et al., "Factors associated with musculoskeletal disorders among nurses at Viet-Tiep hospital in Hai Phong," Journal of Preventive Medicine, no. XXV (11-171), pp. 114-121, 2015.

[20] I. Kuorinka, B. Jonsson, A. Kilbom et al., "Standardised Nordic questionnaires for the analysis of musculoskeletal symptoms," Applied Ergonomics, vol. 18, no. 3, pp. 233-237, 1987.

[21] L. López-Aragón, R. López-Liria, Á. Callejón-Ferre, and M. Gómez-Galán, "Applications of the Standardized Nordic Questionnaire: A Review," Sustainability, vol. 9, no. 9, p. 1514, 2017. 
[22] T. H. Nguyen and V. H. Pham, "Validation of two instruments to measure work - family conflict and psychological distress in vienamese," Journal of Preventive Medicine, no. XXIV (9-158), pp. 96-103, 2014.

[23] R. C. Kessler, P. R. Barker, L. J. Colpe et al., "Screening for serious mental illness in the general population," Archives of General Psychiatry, vol. 60, no. 2, pp. 184-189, 2003.

[24] T. Rousseau, S. Arezki, P. Bérard et al., Outils Et Méthodes Pour Agir, ANACT Lyon, 2009.

[25] T. G. Hoang, M. Corbière, A. Negrini, M. K. Pham, and D. Reinharz, "Validation of the Karasek-Job Content Questionnaire to measure job strain in Vietnam," Psychological Reports, vol. 113, no. 2, pp. 363-379, 2013.

[26] R. PINAR, "Work-Related Musculoskeletal Disorders in Turkish Hospital Nurses," Turkiye Klinikleri Journal of Medical Sciences, vol. 30, no. 6, pp. 1869-1875, 2010.

[27] M. Israni, N. Vyas, and M. Sheth, "Prevalence of musculoskeletal disorders among nurses," The Indian Journal of Physiotherapy \& Occupational Therapy, vol. 1, no. 2, pp. 52-55, 2013.

[28] Y. Chung, C. Hung, S. Li et al., "Risk of musculoskeletal disorder among Taiwanese nurses cohort: a nationwide populationbased study," BMC Musculoskeletal Disorders, vol. 14, no. 1, 2013.

[29] W. Mynarski, M. Grabara, A. Nawrocka, M. Niestrój-Jaworska, B. Wołkowycka, and J. Cholewa, "Physical recreational activity and musculoskeletal disorders in nurses," Medycyna Pracy, vol. 65, no. 2, pp. 181-188, 2014.

[30] B. M. Tinubu, C. E. Mbada, A. L. Oyeyemi, and A. A. Fabunmi, "Work-related musculoskeletal disorders among nurses in Ibadan, South-west Nigeria: a cross-sectional survey," $B M C$ Musculoskeletal Disorders, vol. 11, article 12, 2010.

[31] T. Freimann, D. Coggon, E. Merisalu, L. Animägi, and M. Pääsuke, "Risk factors for musculoskeletal pain amongst nurses in Estonia: a cross-sectional study," BMC Musculoskeletal Disorders, vol. 14, article 334, 2013.

[32] D. R. Smith, M. Mihashi, Y. Adachi, H. Koga, and T. Ishitake, "A detailed analysis of musculoskeletal disorder risk factors among Japanese nurses," Journal of Safety Research, vol. 37, no. 2, pp. 195-200, 2006.

[33] F. A. Rathore, R. Attique, and Y. Asmaa, "Prevalence and Perceptions of Musculoskeletal Disorders Among Hospital Nurses in Pakistan: A Cross-sectional Survey," Cureus, vol. 9, no. 1, 2017.

[34] W. Thinkhamrop and W. Laohasiriwong, "Factors associated with musculoskeletal disorders among registered nurses: Evidence from the thai nurse cohort study," Kathmandu University Medical Journal, vol. 13, no. 51, pp. 247-252, 2015.

[35] N. A. Amin, R. Nordin, Q. K. Fatt, R. M. Noah, and J. Oxley, "Relationship between Psychosocial Risk Factors and WorkRelated Musculoskeletal Disorders among Public Hospital Nurses in Malaysia," Annals of Occupational and Environmental Medicine, vol. 26, no. 1, 2014.

[36] F. Asghar, S. Ehsan, and H. S. Arshad, "Frequency of Work Related Musculoskeletal Disorders among Nurses Working in Hospitals of Lahore," International Journal of Science and Research (IJSR), vol. 5, no. 5, pp. 346-349, 2016.

[37] H. Taghinejad, A. Azadi, Z. Suhrabi, and M. Sayedinia, "Musculoskeletal Disorders and Their Related Risk Factors Among Iranian Nurses," Biotechnology and Health Sciences, vol. 3, no. 1, 2016.

[38] S. S. Yeung, A. Genaidy, and L. Levin, "Prevalence of musculoskeletal symptoms among Hong Kong nurses," Occupational Ergonomics, vol. 4, no. 3, pp. 199-208, 2004.
[39] R. Mehrdad, J. T. Dennerlein, M. Haghighat, and O. Aminian, "Association between psychosocial factors and musculoskeletal symptoms among Iranian nurses," American Journal of Industrial Medicine, vol. 53, no. 10, pp. 1032-1039, 2010.

[40] F. Serranheira, M. Sousa-Uva, and A. Sousa-Uva, "Hospital nurses tasks and work-related musculoskeletal disorders symptoms: a detailed analysis," Work, vol. 51, no. 3, pp. 401-409, 2015.

[41] B. Skela-Savič, K. Pesjak, and S. Hvalič-Touzery, "Low back pain among nurses in Slovenian hospitals: cross-sectional study," International Nursing Review, vol. 64, no. 4, pp. 544-551, 2017.

[42] D. R. Smith, N. Wei, L. Kang, and R.-S. Wang, "Musculoskeletal disorders among professional nurses in Mainland China," Journal of Professional Nursing, vol. 20, no. 6, pp. 390-395, 2004.

[43] M. Rzewuska, C. D. Mallen, V. Y. Strauss, J. Belcher, and G. Peat, "One-year trajectories of depression and anxiety symptoms in older patients presenting in general practice with musculoskeletal pain: A latent class growth analysis," Journal of Psychosomatic Research, vol. 79, no. 3, pp. 195-201, 2015.

[44] M. T. del Campo, P. E. Romo, R. E. de la Hoz, J. M. Villamor, and I. Mahíllo-Fernández, "Anxiety and depression predict musculoskeletal disorders in health care workers," Archives of Environmental \& Occupational Health, vol. 72, no. 1, pp. 39-44, 2016.

[45] A. Z. Loh, J. S. Tan, M. W. Zhang, and R. C. Ho, “The Global Prevalence of Anxiety and Depressive Symptoms Among Caregivers of Stroke Survivors," Journal of the American Medical Directors Association, vol. 18, no. 2, pp. 111-116, 2017.

[46] X. Zhang, Q. Wang, Y. Wang et al., "Duloxetine prevents the effects of prenatal stress on depressive-like and anxiety-like behavior and hippocampal expression of pro-inflammatory cytokines in adult male offspring rats," International Journal of Developmental Neuroscience, vol. 55, pp. 41-48, 2016.

[47] C. Vida, E. M. González, and M. De la Fuente, "Increase of oxidation and inflammation in nervous and immune systems with aging and anxiety," Current Pharmaceutical Design, vol. 20, no. 29, pp. 4656-4678, 2014.

[48] A. Lorusso, S. Bruno, and N. L'Abbate, "A review of low back pain and musculoskeletal disorders among Italian nursing personnel," Industrial Health, vol. 45, no. 5, pp. 637-644, 2007.

[49] H. Harcombe, D. McBride, S. Derrett, and A. Gray, "Physical and psychosocial risk factors for musculoskeletal disorders in New Zealand nurses, postal workers and office workers," Injury Prevention, vol. 16, no. 2, pp. 96-100, 2010.

[50] W.-L. Chen, S.-Y. Chou, S.-C. Yuan et al., "Factors affecting musculoskeletal disorders among hospital nurses," Taiwan Journal of Medicine, vol. 11, no. 4, pp. 252-260, 2006.

[51] M. Barzideh, A. Choobineh, and H. Tabatabaee, "Job stress dimensions and their relationship to musculoskeletal disorders in Iranian nurses," Work, vol. 47, no. 4, pp. 423-429, 2014. 


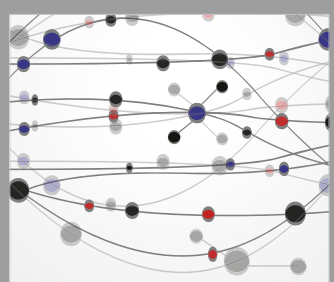

The Scientific World Journal
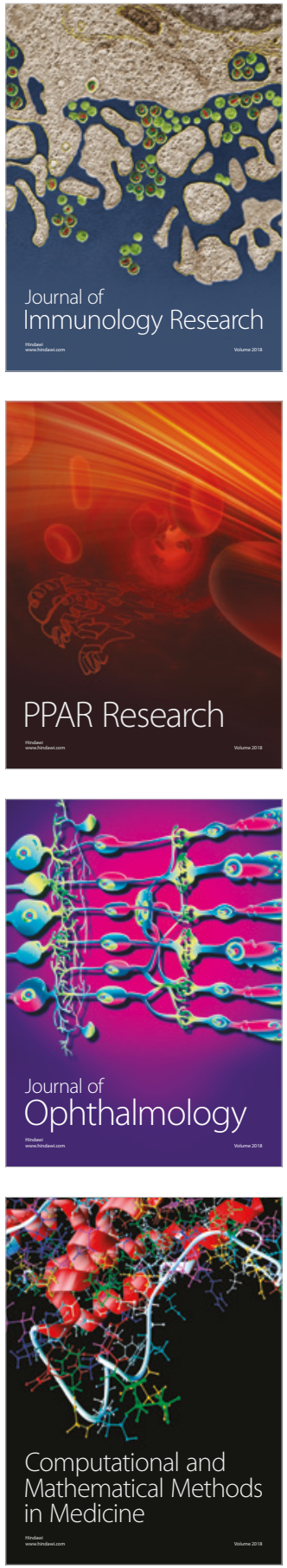

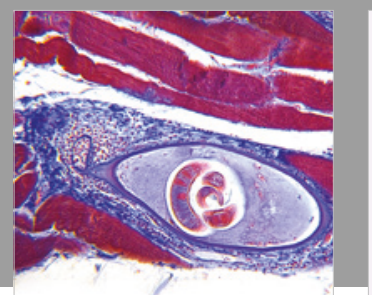

Gastroenterology Research and Practice

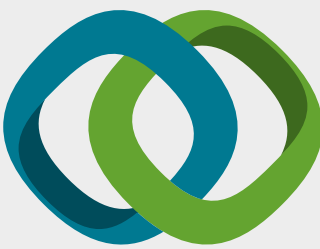

\section{Hindawi}

Submit your manuscripts at

www.hindawi.com
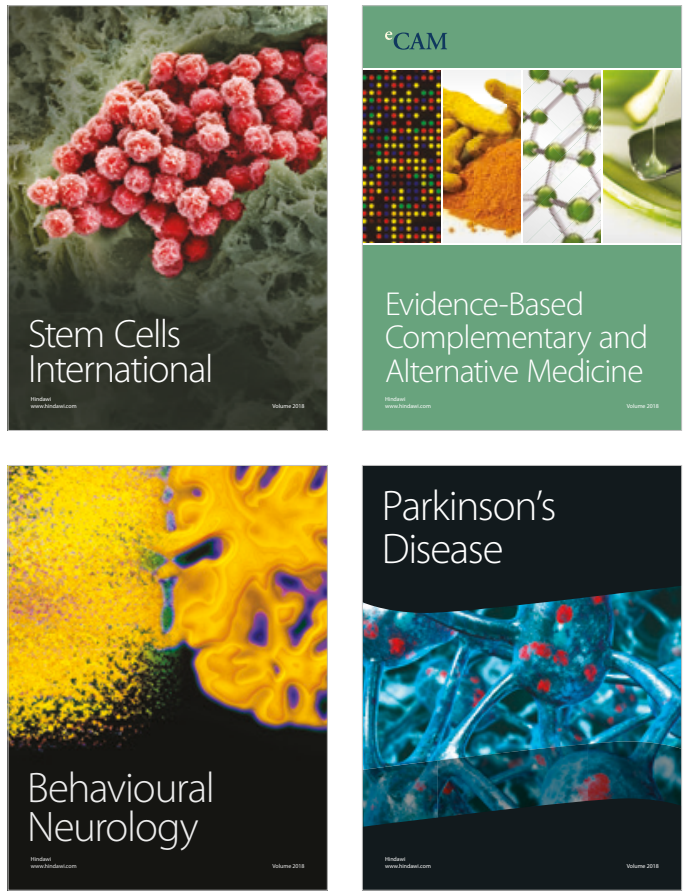

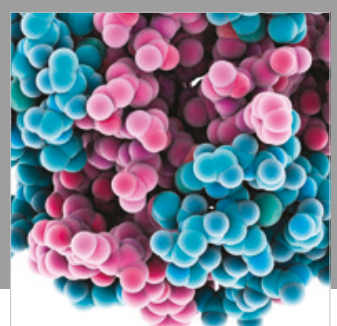

ournal of

Diabetes Research

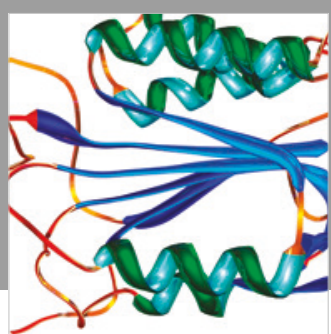

Disease Markers
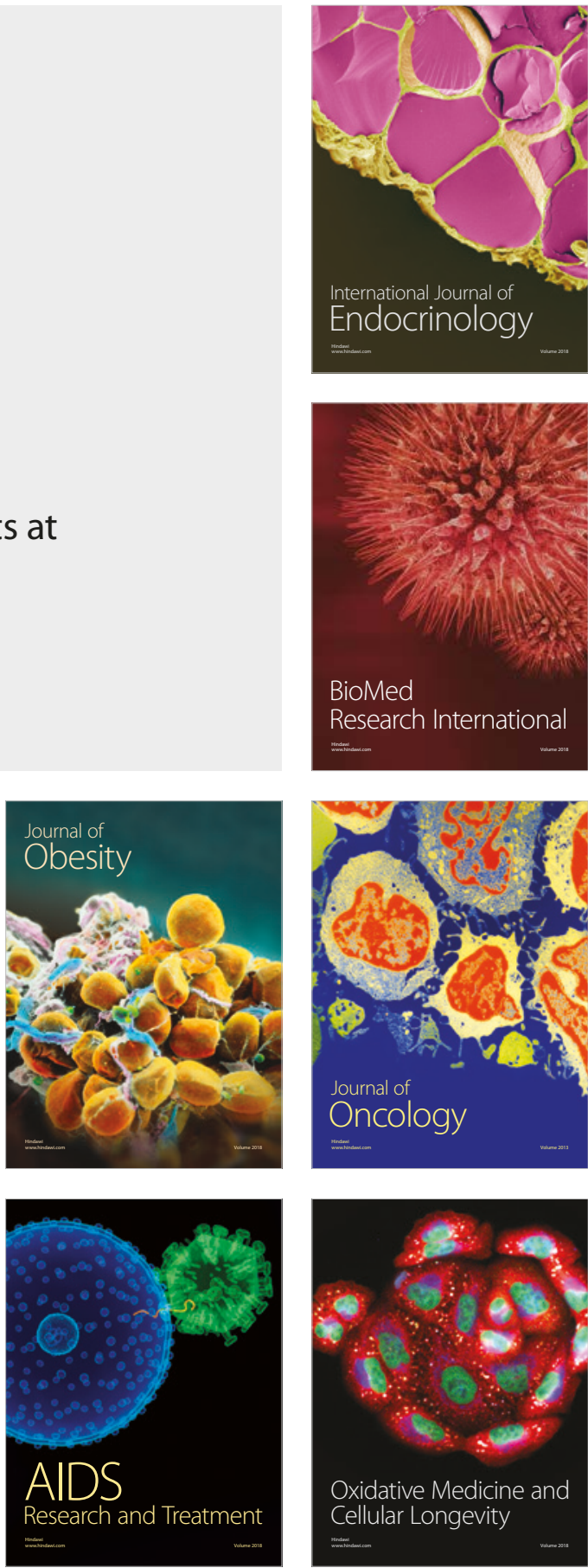